\title{
Evaluation of a Wearable Monitor for Measuring Real-Time Diesel Particulate Matter Concentrations in Several Underground Mines
}

\author{
J. D. Noll and S. Janisko \\ U.S. Department of Health and Human Services, Public Health Service, Centers for Disease Control and \\ Prevention, National Institute for Occupational Safety and Health, Pittsburgh Research Laboratory, \\ Pittsburgh, Pennsylvania
}

\begin{abstract}
The standard method for determining diesel particulate matter (DPM) exposures in underground metal/nonmetal mines provides the average exposure concentration for an entire working shift, and it can take weeks to obtain results. This approach is problematic because, although it reports that an overexposure has occurred, it fails to provide critical information about cause or prevention. Conversely, real-time measurement would provide miners with timely information to identify the major factors contributing to overexposures and would allow engineering controls to be deployed immediately. Due to these potential benefits, the National Institute for Occupational Safety and Health (NIOSH) developed a wearable instrument that measures real-time elemental carbon (EC) concentrations (EC is a DPM surrogate) via laser extinction. This instrument was later constructed into a commercial version (Airtec). This article evaluates the Airtec's performance in several underground metal/nonmetal mines by comparing it to the standard method for determining DPM exposures (NIOSH method 5040). The instrument was found to meet the NIOSH accuracy criteria and to show no statistical difference from NIOSH method 5040 results. In addition, the instrument's measurements were found to be unaffected by dust and humidity.
\end{abstract}

Keywords diesel, measurement, real-time

Address correspondence to: J. D. Noll, U.S. Department of Health and Human Services, Public Health Service, Centers for Disease Control and Prevention, National Institute for Occupational Safety and Health, Pittsburgh Research Laboratory, 626 Cochrans Mill Road, Pittsburgh, PA 15236; e-mail: JIN1@cdc.gov.

\section{INTRODUCTION}

$\mathrm{E}$ xposure to diesel particulate matter (DPM) is a health concern for miners because it has been classified as a potential occupational carcinogen by the National Institute for Occupational Safety and Health (NIOSH) and as likely to be carcinogenic to humans by the Environmental Protection
Agency (EPA). ${ }^{(1-5)}$ In addition, diesel exhaust has been potentially linked to other chronic and acute adverse health effects such as asthma, eye irritation, nausea, and headaches. ${ }^{(6-8)}$ Since underground miners work alongside diesel equipment in a confined environment, they can be exposed to some of the highest levels of diesel exhaust in the country. ${ }^{(2,9)}$ Therefore, the Mine Safety and Health Administration (MSHA) promulgated a rule to limit exposures of metal/nonmetal underground miners to DPM to an 8-hr time-weighted average (TWA) of $160 \mu \mathrm{g} / \mathrm{m}^{3}$ total carbon (TC). ${ }^{(10,11)}$

The standard method for determining DPM exposures is to collect the particulate onto a quartz fiber filter for an entire shift using a submicron impactor to segregate dust from DPM. The sample is then sent to a laboratory to be analyzed for elemental and total carbon using NIOSH method 5040. TC is used as a surrogate to determine DPM exposures since direct DPM measurement is not accurate enough and since TC represents over $80 \%$ of DPM. ${ }^{(11-13)}$ However, non-DPM organic aerosols such as cigarette smoke and oil mist can influence TC concentrations. ${ }^{(14)}$ Therefore, in some cases, MSHA uses submicron elemental carbon (EC) as an alternative surrogate for DPM because it is a major component of DPM, and it eliminates the interference from aerosols containing organic carbon. A worker's 8-hr TWA exposure level is measured in terms of TC concentration and, in order to avoid the influence of interferences, is determined in two ways: (1) a TC value is directly measured using a personal sample, and (2) a TC value is calculated by multiplying the EC value from the personal sample by a conversion factor (determined from an area sample). ${ }^{(15)}$ Both TC values have to be over the permissible exposure limit (PEL) for the mine to be out of compliance.

Although NIOSH method 5040 is an accurate method for determining DPM exposures, it only provides the average concentration over an entire working shift, and the results can take weeks to obtain. This approach is problematic because, although it reports that an overexposure has occurred, it fails to 
provide critical information about cause or prevention. Conversely, real-time measurement would provide miners with timely information to identify the major factors contributing to overexposures and would allow engineering controls to be deployed immediately. As an example, NIOSH method 5040 would take weeks to assess the effect a ventilation strategy has had on actual DPM concentrations. By the time the data is analyzed, the miners could be working in different sections of the mine, and the ventilation could be different due to changes in atmospheric conditions. Real-time analysis would allow ventilation to be redirected to provide timely DPM dilution.

To address the above issues, NIOSH developed an instrument to measure real-time EC exposure via laser extinction. ${ }^{(16-19)}$ EC was chosen as the analyte because it makes up a major portion of DPM, is not prone to interferences, and is one of the surrogates used by MSHA for compliance sampling. Filter-based laser extinction was determined to be a feasible method because EC concentrations are proportional to laser absorption and because this simple technique can be adapted into a small instrument. The Airtec measures light extinction, which incorporates the effects of light absorption and scattering. With DPM particles only, the absorption will be the dominant effect on light extinction. Light scattering may have more of an influence if other scattering aerosols are collected with the DPM (see the interference section under Methods for more detail). ${ }^{(19,20)}$ For example, light scattering from some non-absorbing aerosols can enhance the absorption of the DPM particles. With a preliminary data set, the firstgeneration instrument demonstrated good agreement (within $10 \%$ ) with the standard method for measuring EC from DPM (NIOSH method $5040^{(21)}$ ) in laboratory and limited field studies. ${ }^{(16-18)}$

Taking into account what was learned from the laboratory and field testing on a prototype beta model, a commercial version was developed, tested, and is now available from FLIR, Inc. Laboratory tests have shown that the commercial version (known as Airtec) meets the NIOSH accuracy criteria and has the capability to measure DPM at concentrations commonly observed in underground metal/nonmetal mines. ${ }^{(19)}$ The study also showed that a submicron impactor should be used to avoid the interference of mineral dust and that oil mist and humidity did not affect the Airtec readings. Cigarette smoke was also revealed as a potential interference when sampling a smoker inside an enclosed cab.

The purpose of this study was to evaluate the performance of the Airtec in the field. The accuracy of the instrument when operating in actual working mines was assessed, as was the variability of measurements relative to that of the standard method. In addition, the effects of dust and humidity were also evaluated.

\section{METHODS}

\section{Comparison to NIOSH Method 5040}

Before commercial Airtec units were available, the firstgeneration or beta units constructed by NIOSH and FLIR
(Figure 1) were compared to the standard method for measuring DPM exposures by running them along with two to three NIOSH method 5040 samples in various areas in four metal and seven stone mines. In the beta models, a diaphragm pump draws ambient air at $1.71 \mathrm{pm}$, which enables a preselector to make a $0.8-\mu \mathrm{m}$ size cut. Conductive tubing allows EC to reach the Teflon filter without attaching to the tubing walls. A Teflon filter is housed in a specially designed cassette that includes a defined volume chamber as well as a carefully constructed flow path to achieve uniform distribution of EC on the Teflon filter. A laser penetrates through the sample while collecting DPM, and the optical density (-log(transmittance)) of the laser's energy is measured and converted to $\mu \mathrm{g}$ of EC collected on the filter using a calibration curve established in previous laboratory studies. ${ }^{(16-18)}$ The beta models provided 5-min, 10-min, and 15-min rolling averages as well as the 8-hr time-weighted average as described by Noll et al. ${ }^{(19)}$ The 8 -hr time-weighted average was used to compare the beta model samples with the NIOSH method 5040 samples.

The sampling train for NIOSH method 5040 samples consists of a Dorr-Oliver cyclone followed by SKC DPM cassettes (consisting of two quartz fiber filters in tandem inside an impactor with a cutpoint of $0.8 \mu \mathrm{m}$ at $1.7 \mathrm{lpm}$ ) with flow powered by an MSA Elf pump via tubing. The DPM samples are then analyzed for EC concentration via thermal-optical analysis (following procedures outlined in NIOSH method 5040). This same sampling setup is used for regulatory compliance measurements in underground metal and nonmetal mines. The NIOSH method 5040 results were converted to an 8-hr time-weighted average.

Based on lessons learned after evaluating the beta model, a commercial unit was manufactured with improvements. These improvements included a quieter pump, a different casing to incorporate an internal battery and decrease size, and a metal clip instead of a plastic one. The revised commercial version (Airtec) (Figure 2) was then tested, using the same procedures as with the beta models, at three stone mines under different

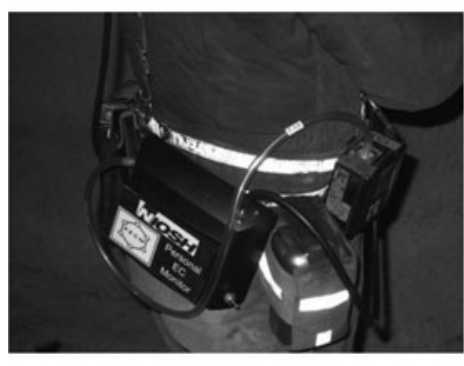

(a)

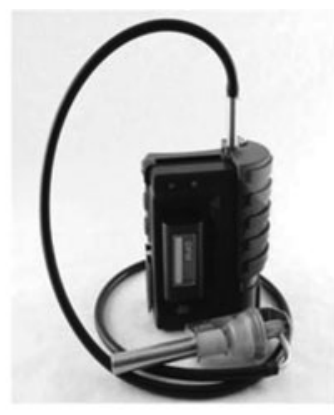

(b)
FIGURE 1. The prototype (beta) models of the wearable instrument for measuring real-time elemental carbon concentrations: (a) constructed by NIOSH (b) constructed by FLIR. 

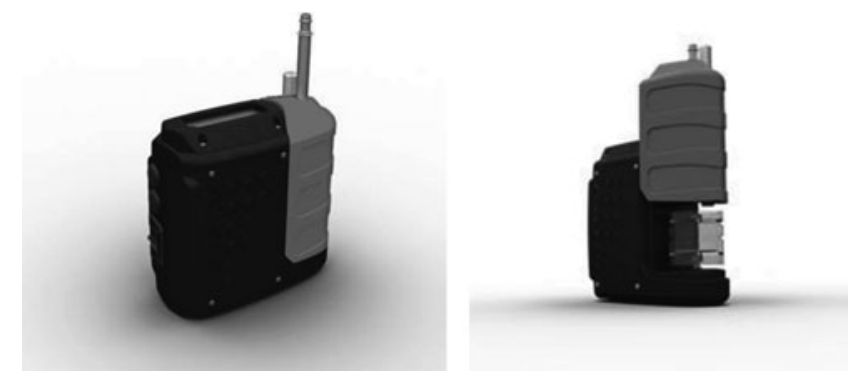

FIGURE 2. The commecial version (Airtec) of the real-time DPM monitor.

conditions (Table I). Area samples consisting of three SKC DPM cassettes for NIOSH method 5040 analysis (using the same setup as described for the beta testing) and at least one Airtec were inserted in a basket, hung along the rib, or placed on a tripod in an area of a mine. In other cases, the same types of samplers were inserted in a basket or connected to a metal plate and then attached to a vehicle or placed inside an enclosed cab.

The bias between NIOSH method 5040 and the Airtecs was calculated using the equations found in Kennedy et al. ${ }^{(22)}$ The $95 \%$ confidence interval for the bias was determined by multiplying the t-value by the standard deviation and dividing by the square root of the number of samples. ${ }^{(23,24)}$

Analytical method errors, pump errors, and matrix effects can all affect the accuracy of the instrument. In underground mines, another source of error (spatial variability) can cause a difference between side-by-side samplers even if both are reading accurately. In fact, spatial variability can lead to measurement biases of over 20\%. ${ }^{(25,26)}$ Therefore, in this study, the Airtec and NIOSH method 5040 results were compared using a method that takes spatial variability into account. The bias between the Airtec and NIOSH method 5040 and the percent difference between duplicate NIOSH method 5040 samples (randomly chosen from the triplicate samples) were compared. If the Airtec is equivalent to NIOSH method 5040, the variability between the Airtec and NIOSH method 5040 results should be similar to the variability between two NIOSH method 5040 samples since both experience similar spatial variability. This evaluation was performed by comparing the

TABLE I. Samples Collected With Airtec

\begin{tabular}{|c|c|c|c|c|}
\hline $\begin{array}{l}\text { Type of } \\
\text { Mine }\end{array}$ & Mine & $\begin{array}{c}\text { Area } \\
\text { Sample }\end{array}$ & $\begin{array}{c}\text { On Vehicle } \\
\text { Sample }\end{array}$ & $\begin{array}{c}\text { In Enclosed } \\
\text { Cab }\end{array}$ \\
\hline Limestone & B & 1 & & \\
\hline Limestone & $\mathbf{J}$ & & 15 & 4 \\
\hline Granite & K & 27 & 21 & \\
\hline Total & & 28 & 36 & 4 \\
\hline
\end{tabular}

median and spread between the biases of the Airtec and NIOSH method 5040 results and the percent differences of duplicate NIOSH method 5040 samples, which were recorded at identical underground locations on the same dates. Since the two data sets were non-normally distributed, the Mann-Whitney rank sum test was performed using Sigma Plot 12.0 instead of the t-test to determine if there are statistical differences between medians. In addition, the Levene's test using Sigma Plot 12.0 instead of an F-test was performed to assess for statistical differences between variances.

\section{Interferences}

Absorbing particles, non-absorbing particles, and humidity have been shown to interfere with filter-based light extinction techniques. ${ }^{(19,20,27)}$ Non-absorbing particles can affect the light extinction by light scattering or can enhance the absorption by multiple scattering, which causes more opportunity for light absorption to occur. ${ }^{(20)}$ The influence of these effects depends on filter type, light wavelength, and aerosol. ${ }^{(19,20)}$ Of the known aerosols present in underground mines, potential interferences are dust, humidity, cigarette smoke, and oil mist. ${ }^{(14)}$

The effects of these interferences on the Airtec were evaluated in a laboratory analysis. ${ }^{(19)}$ These results showed that mineral dust can interfere with the Airtec when no size selector was used, but using a submicron size selector removed the influence of the dust on the Airtec. Even though it is submicron in particle size, oil mist as well as humidity were found not to interfere with the Airtec. The Airtec did not detect the presence of cigarette smoke, another submicron particle, unless DPM was on the filter. This was attributed to multi-scattering of the cigarette smoke particles increasing the opportunities for light absorption from the DPM on the filter. So far, the concentrations of cigarette smoke resulting in a bias to the Airtec were reached only when sampling in enclosed cabs where the equipment operator was smoking. Due to the potential interference of cigarette smoke in some situations, it would have been beneficial to have some samples in the presence of cigarette smoke in the field, but none of the operators in the field studies described in this article were known to smoke within proximity of the sampling locations.

There were locations where the dust concentrations and humidity were measured so that the effects of these on the Airtec measurements could be evaluated in the field. In order to determine if mineral dust affected the Airtec readout, dust measurements as described by Cecala et al. ${ }^{(28)}$ were collected along with the Airtec and NIOSH method 5040 samples in several locations at a limestone mine. Dust concentrations were then compared to biases between the Airtec readings and NIOSH method 5040 results to identify any correlation between the two parameters. The effect of humidity was tested in mines where the humidity was greater than $75 \%$. A Vasaila (Vantaa, Finland) GM70 portable gas monitor, located near the Airtec and NIOSH method 5040 samples, was used to measure relative humidity. 


\section{RESULTS AND DISCUSSION}

\section{Comparison of Airtec with NIOSH Method 5040 in the Field}

The comparison of NIOSH method 5040 samples and the Airtec readings resulted in an average $\%$ bias of $3 \pm 3$ with $96 \%$ of samples having a $\%$ bias within $\pm 25 \%$, and $90 \%$ of the samples having a $\%$ bias within $\pm 16 \%$. This data meets NIOSH accuracy criteria-an average overall bias equal to or less than $10 \%$ and $95 \%$ confidence that the bias will be within $25 \%{ }^{(23)}$ - but may overestimate the bias of the instrument since it does not account for spatial variability, which can result in $20 \%$ error in some cases.

All the Airtec samples at $40 \mu \mathrm{g} / \mathrm{m}^{3} \mathrm{EC}$ and below resulted in a positive bias, with two of the six samples providing biases (>40\%) above the values of the other samples (Figure 3). Whether this phenomenon involves just a few outliers or is caused by environmental issues, such as interferences with greater effects at lower concentrations or higher influence of spatial variability at lower concentrations, cannot be determined at this time, for there are only six points ( 6 out of 68) at and below $40 \mu \mathrm{g} / \mathrm{m}^{3} \mathrm{EC}$.

Given the potential uncertainty for samples at lower concentrations, the biases for all samples greater than $40 \mu \mathrm{g} / \mathrm{m}^{3} \mathrm{EC}$ were also evaluated. These concentrations represent the major- ity of mining samples and contain the PEL (about $120 \mu \mathrm{g} / \mathrm{m}^{3}$ EC). For samples greater than $40 \mu \mathrm{g} / \mathrm{m}^{3} \mathrm{EC}$, the average $\%$ bias was $0.9 \pm 2$ with $95 \%$ of $\%$ biases being within $\pm 16 \%$ and $90 \%$ being within $\pm 13 \%$, even considering potential spatial variability issues.

As described in the Methods section, since the direct comparison of NIOSH method 5040 results and the Airtec readings do not account for spatial variability (potentially resulting in overestimation of the Airtec bias), the biases between the Airtec and NIOSH method 5040 were compared to the differences between side-by-side NIOSH method 5040 samples to determine the equivalency of the Airtec to NIOSH method 5040. The analysis found that the accuracy of the Airtec is not statistically different from the accuracy of side-byside NIOSH method 5040 samples. As seen in Figure 4, the percent biases between the Airtec and NIOSH method 5040 results (range $-18 \%$ to $52 \%$ ) were within the percent differences between duplicate NIOSH method 5040 samples (range $-22 \%$ to $65 \%$ ). The Mann-Whitney rank sum test showed no statistical difference between the medians of the biases of the Airtecs and the percent differences of the NIOSH method 5040 samples. In addition, the Levene's test ( $\mathrm{p}=$ 0.678 ) showed no statistical difference between the spreads or variances of the two data sets.

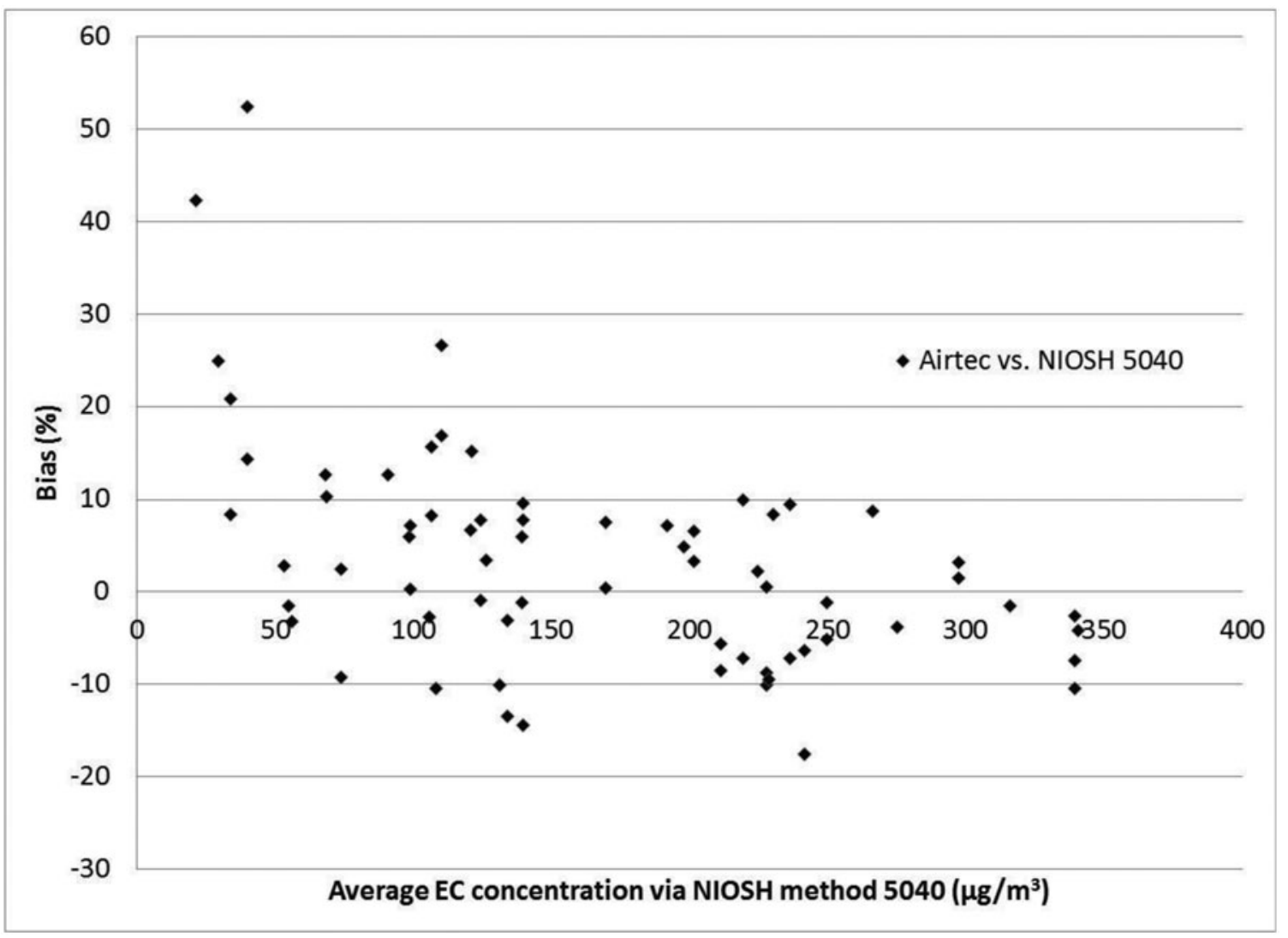

FIGURE 3. The bias between the Airtec and NIOSH method 5040. 
TABLE II. Comparison of Airtec and NIOSH Method 5040 Samples in the Presence of Respirable Dust

\begin{tabular}{|c|c|c|c|c|}
\hline $\mathrm{EC}\left(\mu \mathrm{g} / \mathrm{m}^{3}\right)$ via Airtec & $\begin{array}{c}\mathrm{EC}\left(\mu \mathrm{g} / \mathrm{m}^{3}\right) \text { via } \\
\text { NIOSH } 5040\end{array}$ & $\begin{array}{c}\text { Respirable Dust } \\
\text { Concentration }\left(\mu \mathrm{g} / \mathbf{m}^{\mathbf{3}}\right)\end{array}$ & $\operatorname{Bias}\left(\mu \mathrm{g} / \mathbf{m}^{3}\right)$ & $\%$ Bias \\
\hline 199 & 242 & 190 & -43 & -18 \\
\hline 307 & 298 & 610 & 9 & 3 \\
\hline 302 & 298 & 610 & 4 & 1 \\
\hline 237 & 250 & 770 & -13 & -5 \\
\hline 208 & 202 & 780 & 6 & 3 \\
\hline 77 & 71 & 780 & 6 & 9 \\
\hline 61 & 40 & 1160 & 21 & 52 \\
\hline 46 & 40 & 1160 & 6 & 14 \\
\hline 103 & 106 & 1400 & -3 & -3 \\
\hline
\end{tabular}

\section{Interferences}

As mentioned earlier, interference of dust (when an impactor was used) and humidity was not observed when per- forming the laboratory evaluation on the Airtec (19), and this was validated for some samples in the field. As seen in Table II, bias in the Airtec did not depend on dust concentration when

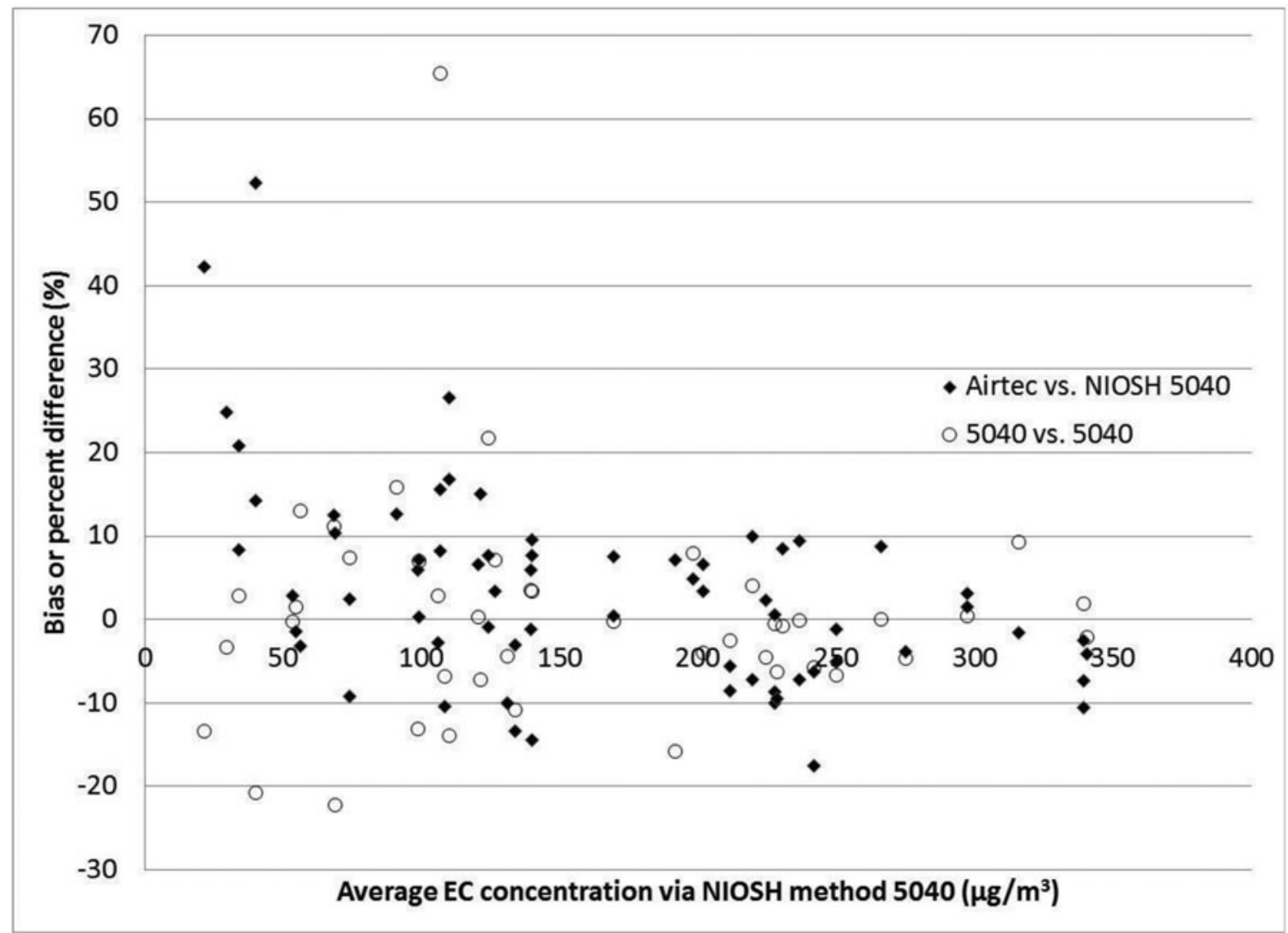

FIGURE 4. The bias between the Airtec and NIOSH method 5040 and the percent difference between duplicate NIOSH method 5040 samples when compared to the average concentration of triplicate NIOSH method 5040 samples. 


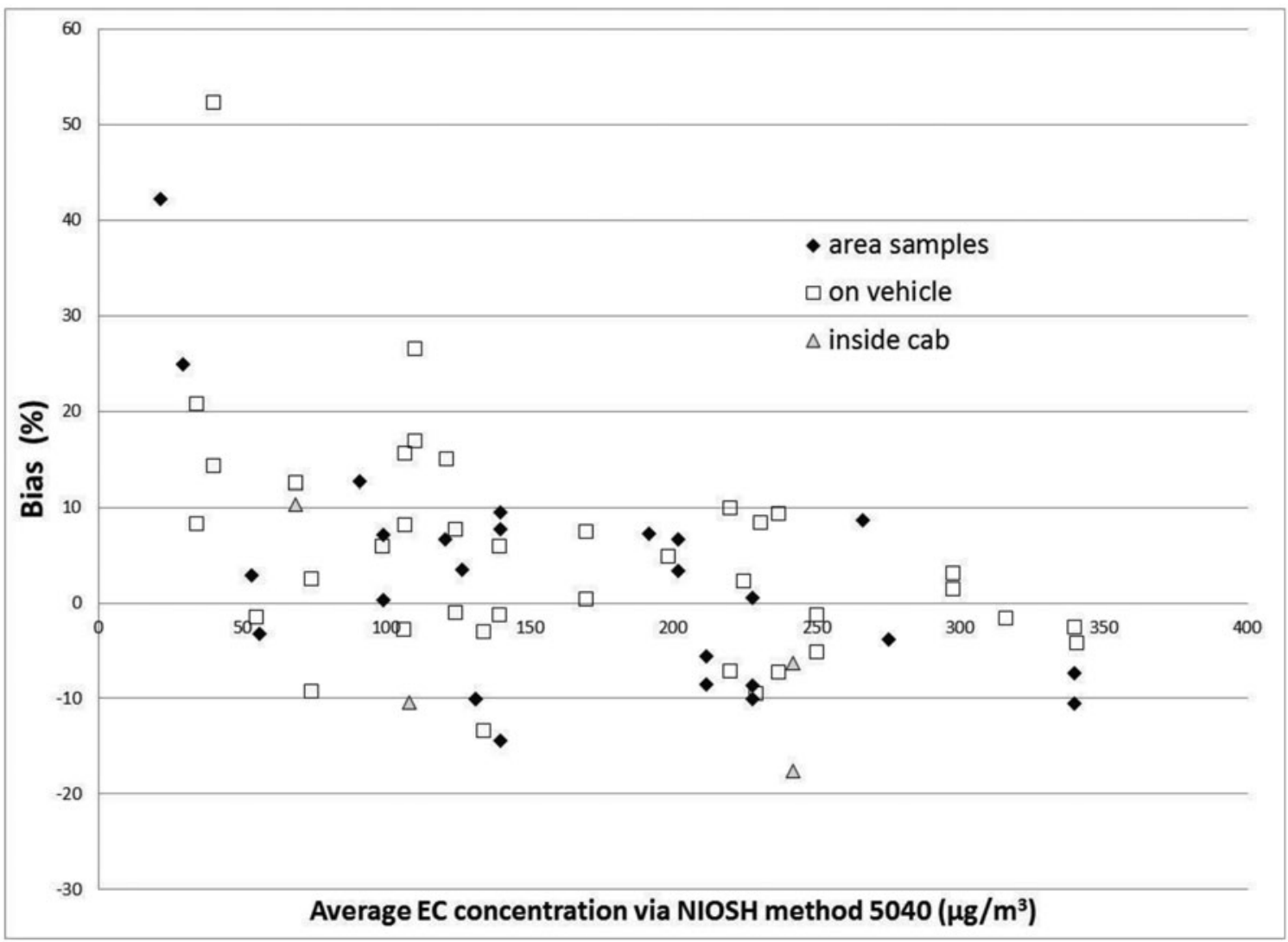

FIGURE 5. The bias between the Airtec and NIOSH method 5040 results vs. the average concentration of triplicate NIOSH method 5040 samples showing the partitioning of the different types of samples.

an impactor was used. This was most evident when the EC concentrations were similar (between 200-250 $\mu \mathrm{g} / \mathrm{m}^{3}$ ) and the dust concentrations were variable (within $190-4,400 \mu \mathrm{g} / \mathrm{m}^{3}$ ). At these parameters, the bias did not increase with concentrations of dust. In addition, a consistent positive or negative bias was not observed due to the presence of dust. Table III shows that high humidity did not cause biases greater than $13 \%$ for EC concentrations between $100-300 \mu \mathrm{g} / \mathrm{m}^{3}$.

During testing, the Airtec was attached to a vehicle that traveled over rough terrain and performed mining tasks, thus

TABLE III. Comparison of Airtec and NIOSH Method 5040 Samples in High Humidity

\begin{tabular}{lccc}
\hline $\begin{array}{l}\mathbf{E C}\left(\mu \mathbf{g} / \mathbf{m}^{\mathbf{3}}\right) \\
\text { via }\end{array}$ & $\begin{array}{c}\mathbf{E C}\left(\boldsymbol{\mu g} / \mathbf{m}^{\mathbf{3}}\right) \\
\text { via NIOSH } \\
\text { Airtec }\end{array}$ & $\begin{array}{c}\text { Relative } \\
\text { Humidity } \\
(\mathbf{5 0 4 0}\end{array}$ & $\begin{array}{c}\text { \% } \\
\text { Bias }\end{array}$ \\
\hline 103 & 91 & 94 & 13 \\
206 & 192 & 78 & 7 \\
289 & 266 & 95 & 9 \\
265 & 275 & 86 & -4 \\
\hline
\end{tabular}

introducing it to a potential interference from vibration. As seen in Figure 5, the results from this field study provided no evidence that vibration affected the Airtec readings; i.e., there was no obvious increase in bias between the Airtec and NIOSH method 5040 results when attached to a vehicle compared to area samples.

\section{CONCLUSION}

T $\mathrm{n}$ this field study, the Airtec readings were shown to be 1 equivalent to NIOSH method 5040 samples. The difference between the Airtec readings and NIOSH method 5040 results were similar to the differences observed when comparing duplicate NIOSH method 5040 samples. When an impactor was used, dust and high humidity did not seem to affect the Airtec readings in the field. In these field studies, another known potential interference (cigarette smoke) was not tested because smoking was not known to occur at the sampling locations. Besides the known potential interferences, if other submicron aerosols are present, they could potentially cause a bias in the Airtec results at high enough concentrations. ${ }^{(19,20)}$ Future studies will address their effects if any additional aerosols that may potentially interfere are identified. 


\section{DISCLAIMER}

$\mathrm{M}$ ention of a company name or product does not constitute an endorsement by the National Institute for Occupational Safety and Health. The findings and conclusions in this report are those of the authors and do not necessarily represent the views of the National Institute for Occupational Safety and Health. This article is not subject to US copyright law.

\section{REFERENCES}

1. National Institute for Occupational Safety and Health (NIOSH): Carcinogenic Effects of Exposure to Diesel Exhaust. Current Intelligence Bulletin No. 50. U.S. Department of Health and Human Services, Public Health Service, Centers for Disease Control and Prevention (Pub. No. 88-116), 1988.

2. U.S. Environmental Protection Agency (EPA): Health Assessment Document for Diesel Engine Exhaust. Prepared by the National Center for Environmental Assessment, Washington, D.C., for the Office of Transportation and Air Quality; EPA/600/8-90/057F. National Technical Information Service, Springfield, Va. (PB2002-107661), 2002 .

3. Neumeyer-Gromen, A., O. Razum, N. Kersten, A. Seidler, and H. Zeeb: Diesel motor emissions and lung cancer mortality-Results of the second follow-up on a cohort study in potash miners. Int. J. Cancer 124:1900-1906 (2009).

4. Pope, C.A., R.T. Burnett, M.J. Thun, et al.: Lung cancer, cardiopulmonary mortality and long-term exposure to fine particulate air pollution. J. Am. Med. Assoc. 287(9):1132-1141 (2002).

5. Attfield, M.D., P.L. Schlieff, J.H. Lubin, et al.: The diesel exhaust in miners study: A cohort mortality study with emphasis on lung cancer. $J$. Natl. Cancer Inst. 104(11):869-883 (2012).

6. Ris, C.: U.S. EPA health assessment for diesel engine exhaust: A review. Inhal. Toxicol. 19:229-239 (2007).

7. Kahn, G., P. Orris, and J. Weeks: Acute overexposure to diesel exhaust: Report of 13 cases. Am. J. Ind. Med. 13(3):405-406 (1988).

8. Wade, J.F., III, and L.S. Newman: Diesel asthma: Reactive airways disease following overexposure to locomotive exhaust. J. Occup. Med. 35:149-154 (1993).

9. Watts, F.W., Jr:: Assessment of Occupational Exposure to Diesel Emissions. In Diesel Exhaust: A Critical Analysis of Emissions, Exposure, and Health Effects. Cambridge, Mass.: Health Effects Institute, 1995. pp. 107-123.

10. "Diesel Particulate Matter Exposure of Underground Metal and Nonmetal Miners; Final Rule. Mine Safety and Health Administration," Federal Register 66:13 (2001). p. 5706.

11. "Diesel Particulate Matter Exposure of Underground Metal and Nonmetal Miners; Final Rule. Mine Safety and Health Administration," Federal Register 71:96 (2006). p. 28924.

12. Pierson, W.R., and W.W. Brachaczek: Particulate matter associated with vehicles on the road. Aerosol Sci. Technol. 2:1-40 (1983).

13. Kittelson, D.B.: Engines and nanoparticles: A review. J. Aerosol Sci. 29:575-588 (1998).
14. Noll, J.D., S. Mischler, G.H. Schnakenberg, and A. Bugarski: Measuring Diesel Particulate Matter in Underground Mines Using Sub Micron Elemental Carbon as a Surrogate. In Proceedings for the $11^{\text {th }}$ US North American Mine Ventilation Symposium, J. Mutmansky and R. Ramani (eds.). State College, Pa.: Taylor \& Francis, 2006. pp. 105-110.

15. U.S. Department of Labor, Mine Safety and Health Administration (MSHA): Enforcement of Diesel Particulate Matter Final Limit at Metal and Nonmetal Underground Mines. Program Policy Letter No. P08-IV-01. Available at www.msha.gov/01-995/DPMComplianceDetermination.pdf (Accessed September 20, 2013).

16. Janisko, S., and J.D. Noll: Near real time monitoring of diesel particulate matter in underground mines. In Proceedings of the 12th U.S./North American Mine Ventilation Symposium, K. Wallace (ed.). Reno, Nev.: Omnipress, 2008. pp. 509-513.

17. Janisko, S., and J.D. Noll: Field evaluation of diesel particulate matter using portable elemental carbon monitors. In Proceedings of the 13th U.S./North American Mine Ventilation Symposium, S. Hardcastle (ed.). Sudbury, Ontario, Canada: MIRARCO-Mining Innovation, 2010. pp. $47-52$.

18. Noll, J.D., and S.J. Janisko: Using laser absorption techniques to monitor diesel particulate matter exposure in underground stone mines. Proc. SPIE 6759:67590P (2007).

19. Noll, J.D., S. Janisko, and S. Mischler: Development of real time diesel particulate monitor. Anal. Methods. 5:2954-2963 (2013).

20. Bond, T.C., T.L. Anderson, and D. Campbell: Calibration and intercomparison of filter-based measurements of visible light absorption by aerosols. Aerosol Sci. Tech. 30:582-600 (1999).

21. Birch, M.E.: NIOSH Manual of Analytical Methods (NMAM), P.F. O'Connor (ed.), Third Supplement to NMAM, 4th Edition. Cincinnati, Ohio: Department of Health and Human Services, Public Health Service, Centers for Disease Control and Prevention, National Institute for Occupational Safety and Health (Publication No. 2003-154), 2004.

22. National Institute for Occupational Safety and Health (NIOSH): Guidelines for Air Sampling and Analytical Method Development and Evaluation, by E.R. Kennedy, T.J. Fischbach, R. Song, P.M. Eller, and S.A. Shulman (Technical Report Publication No. 95-117), 1995.

23. Bartley, D.L., J.E. Slaven, M.C. Rose, M.E. Andrew, and M. Harper: Uncertainty determination for nondestructive chemical analytical methods using field data and application to XRF analysis for lead. J. Occup. Environ. Hyg. 4:931-942 (2007).

24. Skoog, D.A., and D.M. West: Analytical Chemistry, Fourth Edition. Philadelphia, Saunders College Publishing, 1986. pp. 48-49.

25. Vinson, R.P., J.C. Volkwein, and L.J. McWilliams: Determining the spatial variability of personal sampler inlet locations. J. Occup. Environ. Hyg. 4(9):708-714 (2007).

26. Page, S.J., J.A. Organiscak, and T. Mal: The effects of low quartz mass loading and spatial variability on the quartz analysis of surface coal mine dust samples. Appl. Occup. Environ. Hyg. 16(9):910-923 (2001).

27. Arnott, W.P., H. Mossmuller, P.J. Sheridan, et al.: Photoacoustic and filter-based ambient aerosol light absorption measurements: Instrument comparisons and the role of relative humidity. J. Geophysical Res. 108:15-1-15-11 (2003).

28. Cecala, A.B., J.A. Organiscak, and J.D. Noll: Long-term evaluation of cab particulate filtration and pressurization performance. Society for Mining, Metallurgy, and Exploration-2012 Transactions 332:521-531 (2013). 